\title{
Mechanical Properties of a “5+4" Viscoelastic Damping Wall Based on Full-Scale Laboratory Tests
}

\author{
Junhong $\mathrm{Xu}^{1}$ and Aiqun $\mathrm{Li}^{1,2}$ \\ ${ }^{1}$ School of Civil Engineering, Southeast University, Nanjing, Jiangsu 210096, China \\ ${ }^{2}$ Beijing University of Civil Engineering and Architecture, Beijing 100044, China \\ Correspondence should be addressed to Junhong Xu; xujunhong0321@126.com
}

Received 27 July 2015; Accepted 13 October 2015

Academic Editor: Tony Murmu

Copyright (c) $2016 \mathrm{~J}$. Xu and A. Li. This is an open access article distributed under the Creative Commons Attribution License, which permits unrestricted use, distribution, and reproduction in any medium, provided the original work is properly cited.

\begin{abstract}
This paper presented temperature scanning tests of the viscoelastic materials firstly. The temperature scanning tests were carried out by a Rheogel-E4000DMA analyzer and the results showed the modulus and loss factor of viscoelastic damping material. Secondly, the full-scale laboratory test of the " $5+4$ " VDW was carried out. The test was conducted on an electrohydraulic servo tester. A new shear loading mode in the transverse direction was proposed for the VDW. And the maximum damping force, the storage stiffness, the loss stiffness, equivalent damping coefficient, the shear storage modulus, the shear loss modulus, and the loss factor were discussed in the text.
\end{abstract}

\section{Introduction}

Viscoelastic damping devices have been widely used to control vibration of aerospace structures $[1,2]$. Since they were discovered in 1969, these devices have been used in various civil engineering structures as well [3-7]. Viscoelastic damping devices use shear deformation of viscoelastic damping materials that are bonded between steel plates to dissipate vibration (oscillation) energy, blocking it from the structure. This damping is meant to reduce interstory shear, interstory displacement, and floor acceleration of the structures [8-12]. In addition to use for new structures, these damping devices can be used for seismic strengthening of existing structures. In general, viscoelastic damping devices are regarded as some of most effective vibration control devices to improve wind and seismic resistance in civil engineering [13].

In recent years, a large amount of research has been conducted, and many practical projects involving viscoelastic damping devices have been studied. Viscoelastic damping devices with many different configurations have been developed $[6,14-17]$. However, there are still gaps in the research.

One problem is that viscoelastic damping devices are generally tested by temperature-dependent experiments in incubators. There has therefore been a deficit of relevant experiments for energy dissipation materials used in viscoelastic damping devices, especially about the correlation of materials used and temperature.

Another problem is that viscoelastic dampers are commonly used between building stories for support, which significantly limits their application. A viscoelastic damping wall (VDW) could meet the demands of the structure. However, limited research has been conducted on VDWs, especially experimental investigations, which have restricted the application of VDWs in full-scale structures thus far.

In addition, loading tests of viscoelastic damping devices are usually conducted by applying cyclic loads in the long-axis direction. To better match the model of components under actual loading conditions, a new loading method should be developed, that is, shear loading in the transverse direction.

Finally, traditional mechanical property analysis of the components of viscoelastic damping devices is usually focused on modulus and loss factors. As a result, there has been insufficient investigation into the other mechanical properties of viscoelastic damping devices, including the storage stiffness, the loss stiffness, and the equivalent damping coefficient.

Currently, viscoelastic damping devices are widely used as diagonal braces and inverse braces in structures [18, 19]. However, this placement often leads to the axial displacements of the devices at a rate that is less than or equal to the 


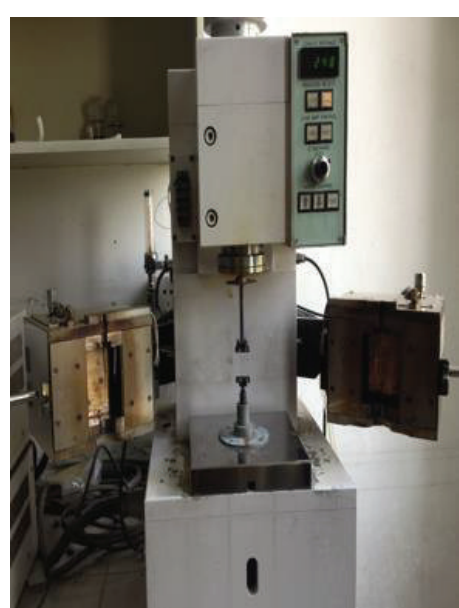

(a) Rheogel-E4000DMA tester

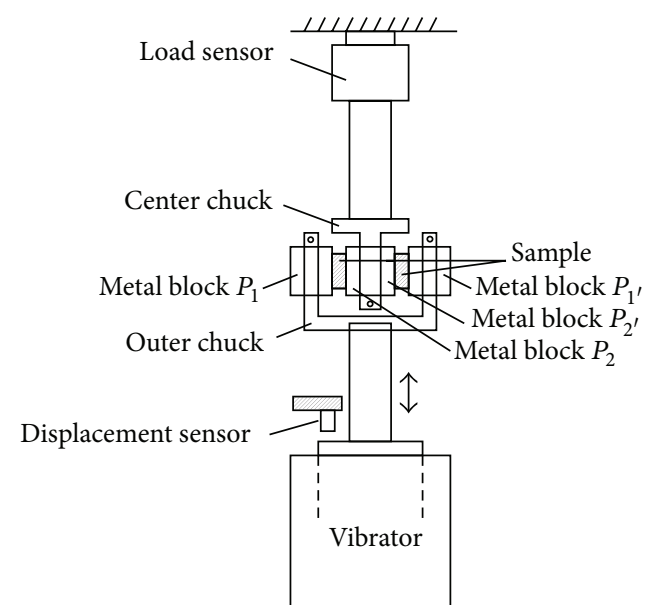

(b) Schematic diagram of sample holder in shear mode

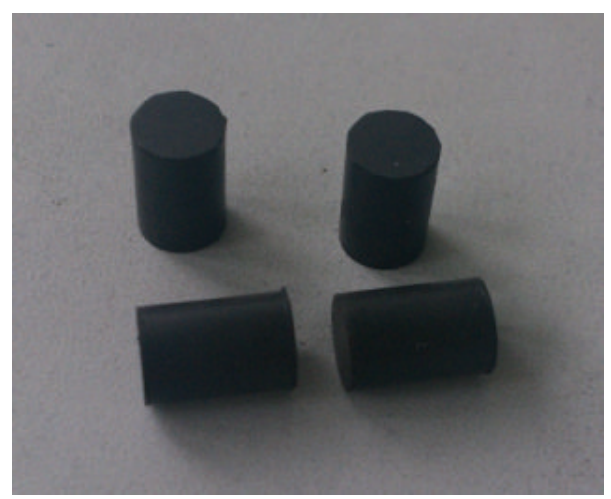

(c) The viscoelastic material used in VDW

FIGURE 1: Temperature scan tester and test specimen for viscoelastic damping material.

interstory displacement, thus lowering the efficiency of the energy dissipation. The axial displacements of novel braces of viscoelastic damping devices, which are based on the Toggle-Brace-Damper [20] and Scissors-Jack-Damper [21], are larger than the structural drift. However, there are some limitations when these novel braces are used. In addition to the difficulties in construction, the instability and the high cost, no doors or windows can be set at the installed location for brace-type devices. Various wall-type devices have thus been proposed and developed, such as wall-type friction devices [22] and viscous wall dampers [23]. In order to increase the area of shear deformation of viscoelastic materials and provide high damping forces, a " $5+4$ " VDW (i.e., four layers of viscoelastic materials sandwiched in five layers of steel plates) is developed in this paper. Subsequently, temperature scanning tests of the viscoelastic materials and full-scale laboratory tests of the " $5+4$ " VDW are carried out and the mechanical parameters are obtained.

\section{Temperature Scan Test of Viscoelastic Damping Material}

To enhance the accuracy of the temperature-dependence test of the viscoelastic damping device, temperature scan tests of viscoelastic damping materials were conducted. Working parameters of the dynamic temperature scan are listed in Table 1.

The dynamic mechanical analysis was carried out by a Rheogel-E4000DMA analyzer, which was manufactured by the UBM Corporation in Japan (Figure 1(a)). Based on the mechanical properties of the viscoelastic damping material, the dynamic shearing mode was used in the tests. A schematic diagram of the loading mechanism is shown in Figure 1(b). Data of the basic mechanical properties of this material were obtained at temperatures ranging from 0 to $40^{\circ} \mathrm{C}$ and also three different frequencies $(0.5,1.5$, and $2.5 \mathrm{~Hz})$. The results are shown in Figure 2. In the figure, $G^{\prime}$ and $G^{\prime \prime}$ represent the storage modulus and the loss modulus of the material, respectively. $\tan \delta$ represents loss factor and it can be seen in Figure 2 that the mechanical properties of this damping material are stable. The glass transition temperatures remained at $\sim 20^{\circ} \mathrm{C}$ for three frequency conditions, and the peak value of the loss factor was 0.79. In addition, the changing trend in the damping property as the temperature was varied is visible from the curves. Therefore, only two factors involving the displacement and the frequency were taken into account in the mechanical property test of the viscoelastic damping structure. 


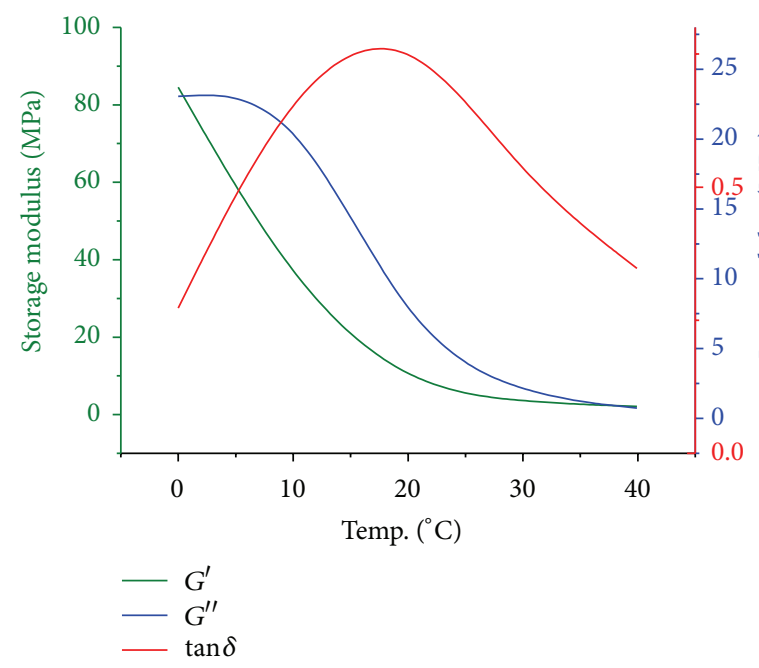

(a) Modulus and loss factor of viscoelastic damping material at $0.5 \mathrm{~Hz}$

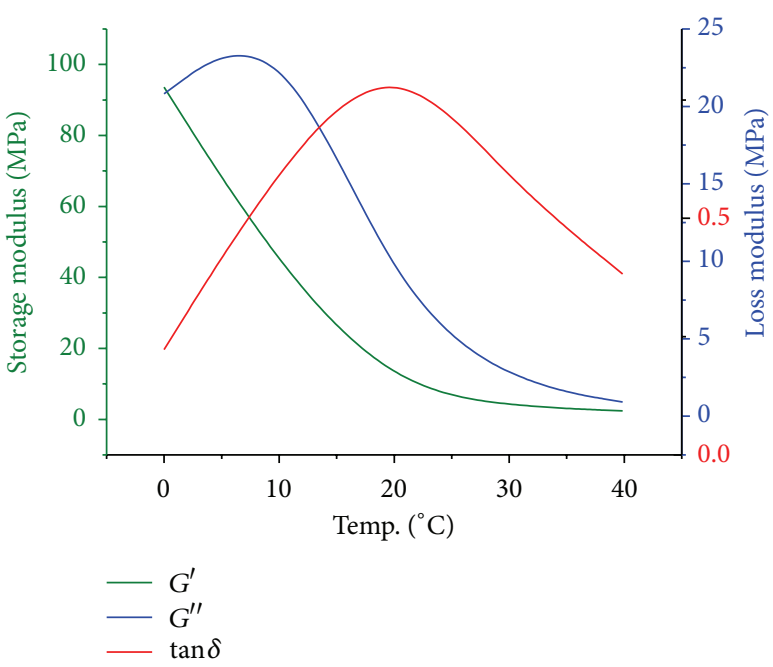

(b) Modulus and loss factor of viscoelastic damping material at $1.5 \mathrm{~Hz}$

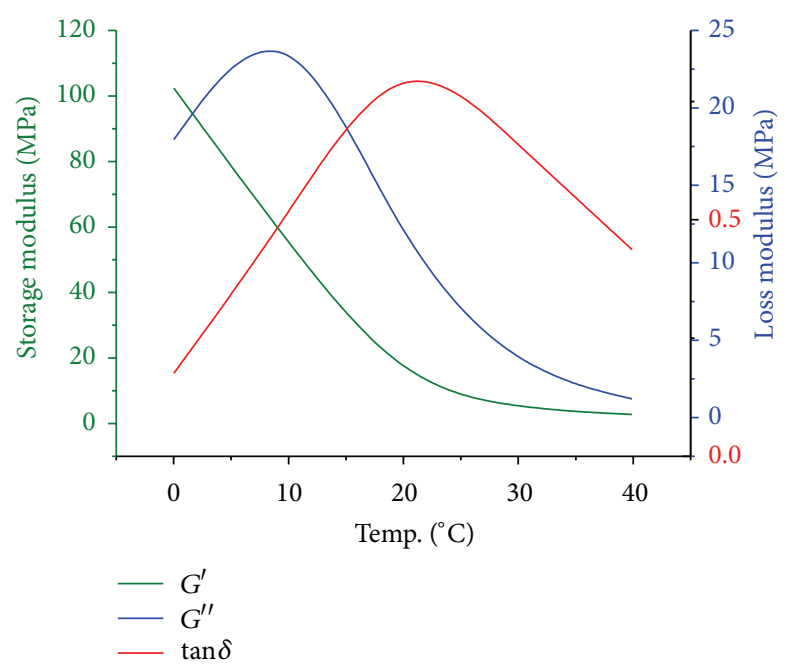

(c) Modulus and loss factor of viscoelastic damping material at $2.5 \mathrm{~Hz}$

FIGURE 2: Basic mechanical property of viscoelastic damping material.

TABLE 1: Working parameters of the dynamic temperature scan.

\begin{tabular}{lc}
\hline Parameter & Value \\
\hline Dynamic displacement & $10 \mu \mathrm{m}$ \\
Frequency & $0.5 \mathrm{~Hz}, 1.5 \mathrm{~Hz}$, and $2.5 \mathrm{~Hz}$ \\
Temperature & $0^{\circ} \mathrm{C}, 10^{\circ} \mathrm{C}, 20^{\circ} \mathrm{C}, 30^{\circ} \mathrm{C}$, and $40^{\circ} \mathrm{C}$ \\
Heating rate & $3^{\circ} \mathrm{C} / \mathrm{min}$ \\
\hline
\end{tabular}

\section{VDW Tests}

3.1. Specification of VDW Component. The VDW is a fullscale model. Its structure and dimensions are shown in Figure 3(a). The thicknesses for each layer of viscoelastic material and central steel plate are $10 \mathrm{~mm}$ and $20 \mathrm{~mm}$, respectively. The thickness of each of the four constraining steel plates on two sides is $12 \mathrm{~mm}$. The effective crosssectional dimensions of the VDW are $500 \mathrm{~mm} \times 500 \mathrm{~mm}$. The viscoelastic material layers cover an area of $10,000 \mathrm{~mm}^{2}$.
The steel plates in the center and at the two sides are $200 \mathrm{~mm}$ longer than the viscoelastic layers at the top and bottom. The total size of the VDW model is $900 \mathrm{~mm} \times 500 \mathrm{~mm}$.

3.2. Device for Shear Loading in the Transverse Direction. A device for providing the shear loads was designed based on the dimensions and specifications of the components mentioned above (see Figure $3(\mathrm{~b})$ ). The entire system is composed of a fixed support on the bottom and a loadapplying fixture on the top. The middle part is the VDW component. The test was conducted on an electrohydraulic servo tester. The hydraulic power units consist of highpressure nitrogen cylinders and a Tobul PA30-240 piston accumulator.

\subsection{Working Conditions and Evaluation Methods of Damping} Properties. According to the industrial standard of Dampers for Vibration Energy Dissipation of Buildings [24], five loading cycles were used. The third hysteresis loop was selected 


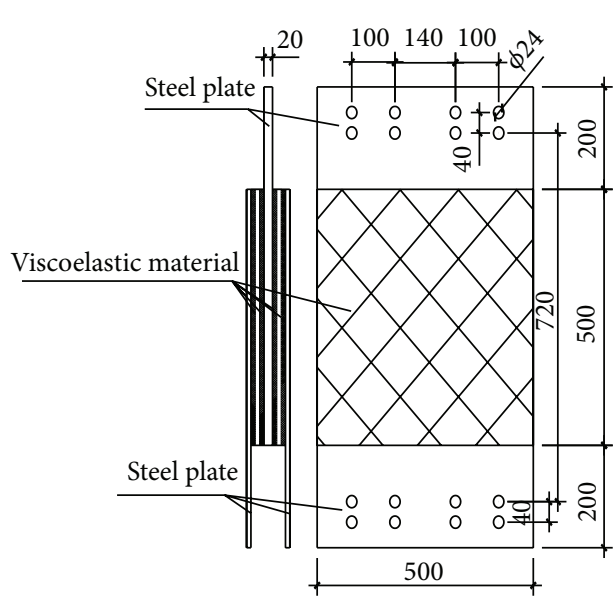

(a) Test specimens of VDW (unit: $\mathrm{mm}$ )

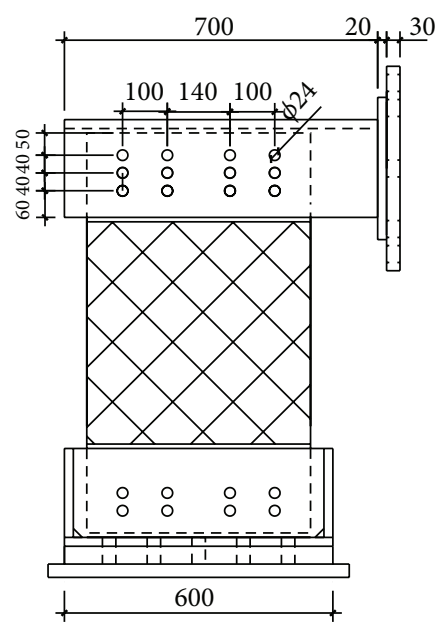

(c) Side view of loading device (unit: $\mathrm{mm}$ )

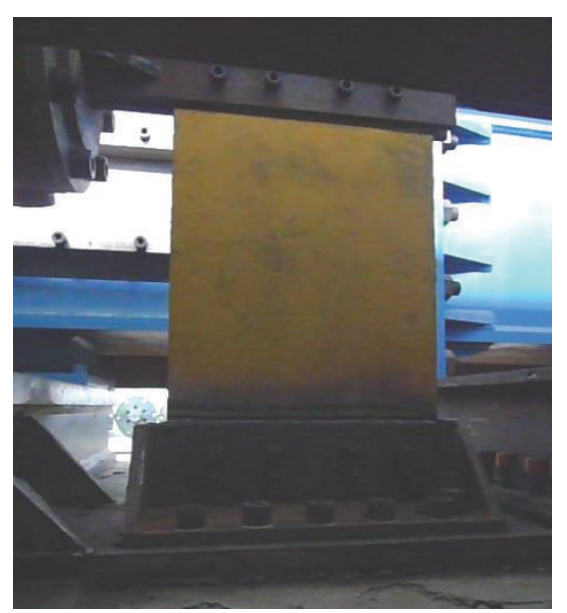

(e) View of the full-scale laboratory test

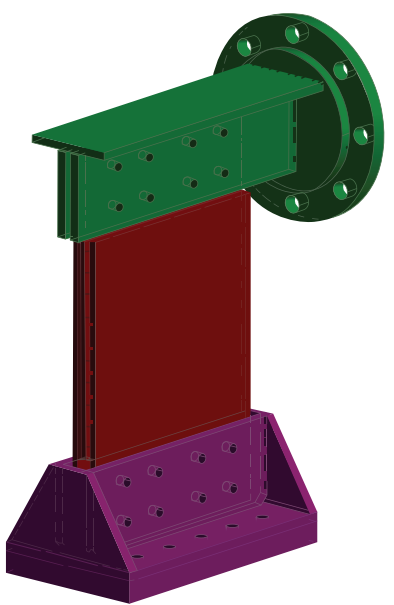

(b) Three-dimensional view of loading device

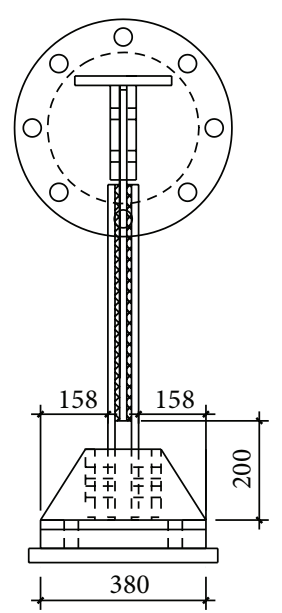

(d) Rear view of loading device 


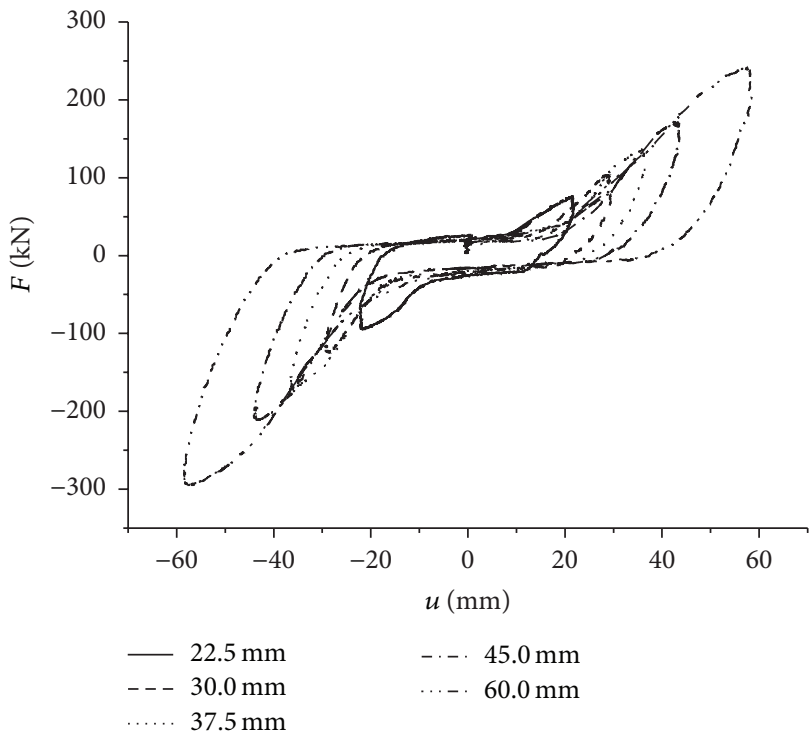

(a) $0.5 \mathrm{~Hz}$

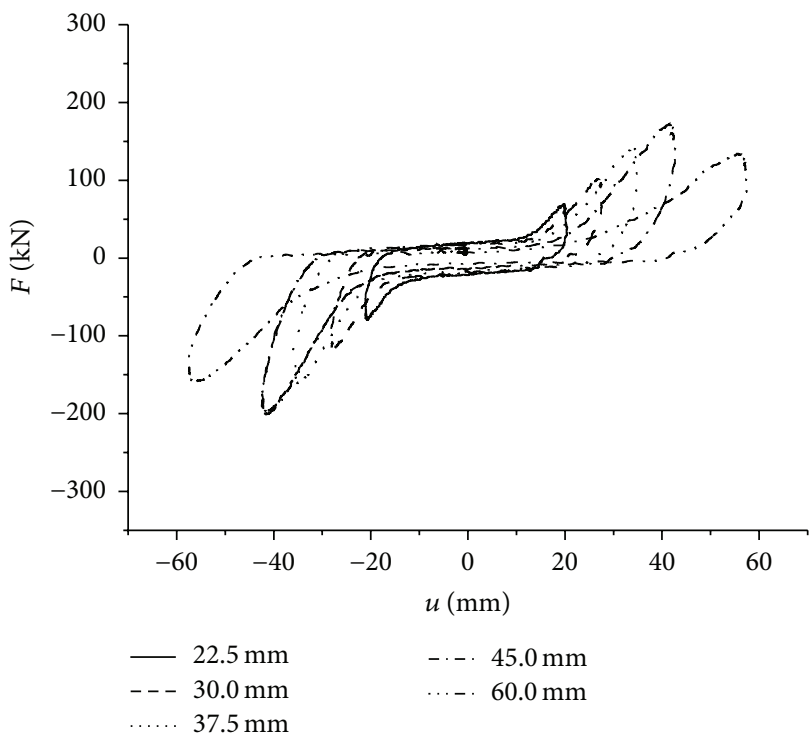

(c) $1.5 \mathrm{~Hz}$

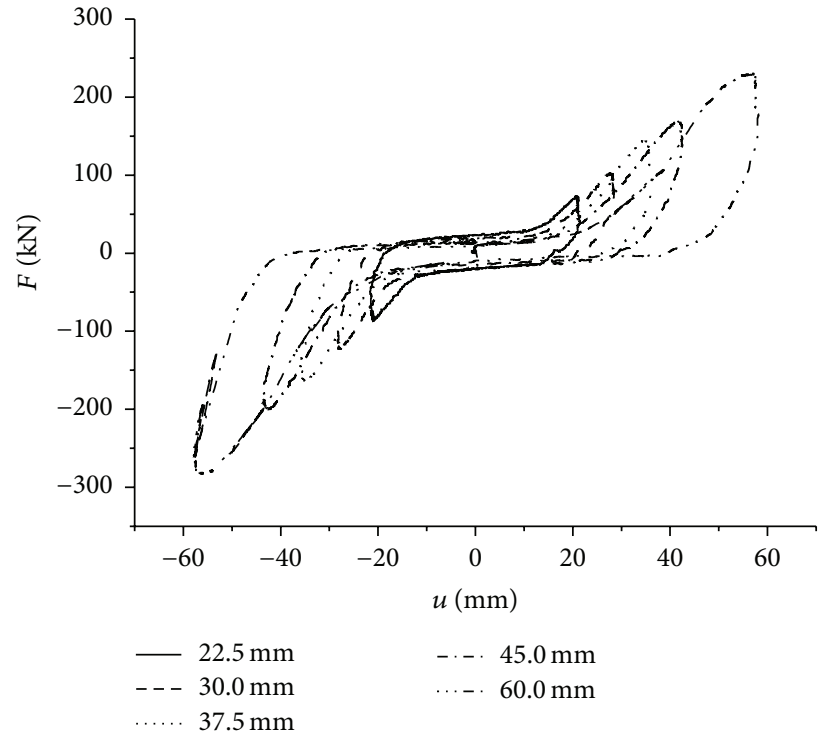

(b) $1.0 \mathrm{~Hz}$

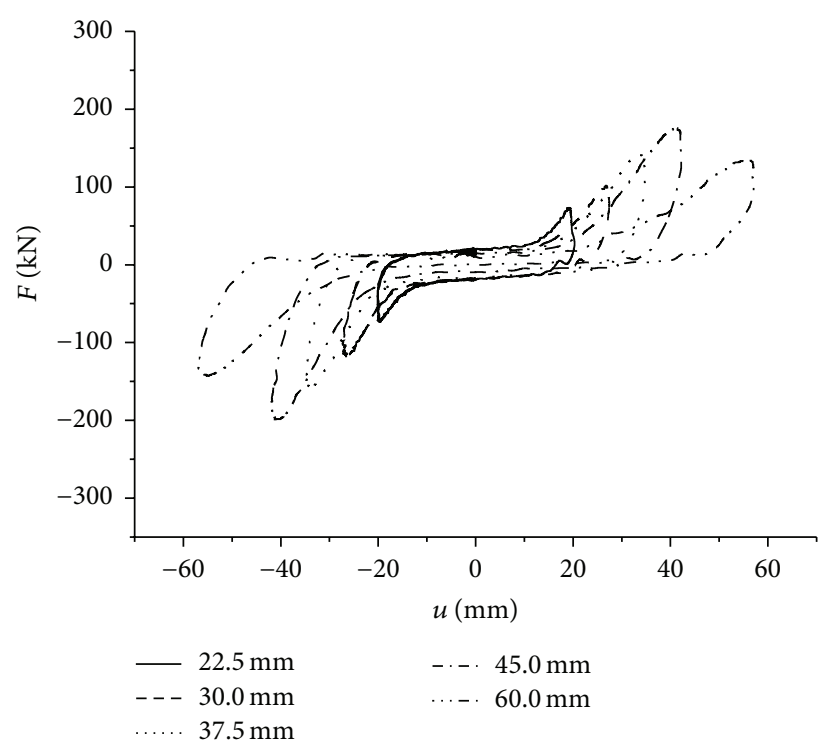

(d) $2.0 \mathrm{~Hz}$

Figure 4: $F-u$ hysteresis curves of VDW at different frequencies and displacements.

as the standard test curve. Experiments were performed at room temperature, and the measured temperature on site was $21.2^{\circ} \mathrm{C}$. The relationships of frequencies and displacements were considered. Four frequencies $(0.5,1.0,1.5$, and $2.0 \mathrm{~Hz})$ and five displacements $(22.5,30.0,37.5,45.0$, and $60.0 \mathrm{~mm})$ were selected for study.

3.4. Force-Displacement Hysteresis Curves. Figure 4 presents the force-displacement $(F-u)$ hysteresis curves under the selected test conditions. Figure 4 does not show an inclined elliptical shape because the viscoelastic materials belonged to $\mathrm{Si}$ content and behaved in a nonlinear viscoelastic manner.

\section{Analyses of Mechanical Properties}

The mechanical properties that this study uses to describe the newly designed VDW include the maximum damping force, the storage stiffness, the loss stiffness, the equivalent damping coefficient, the shear storage modulus, the shear loss modulus, and the loss factor. These values were calculated based on the tested hysteresis curves. Though the forcedeformation loops showed nonlinear behavior, the definition of these mechanical properties exhibited linear behavior [25].

4.1. Maximum Damping Force. The maximum damping force $F_{\text {max }}$ is defined as the maximum load that can be endured by the VDW at a certain displacement. The displacementand frequency-dependence curves of the maximum damping force are shown in Figure 5. It can be seen from Figure 5(a) that the maximum damping force was $241.5 \mathrm{kN}$ when the frequency was $0.5 \mathrm{~Hz}$ and the displacement amplitude was $60.0 \mathrm{~mm}$. The rising slopes of the maximum damping force under four frequency conditions were almost the same. The maximum damping force increased monotonically below 


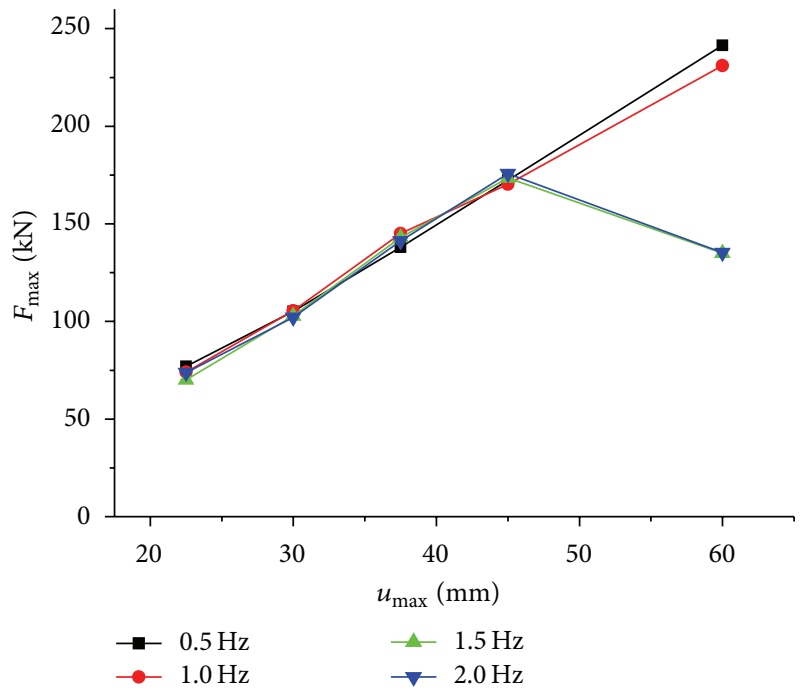

(a) Displacement dependence of the maximum damping force

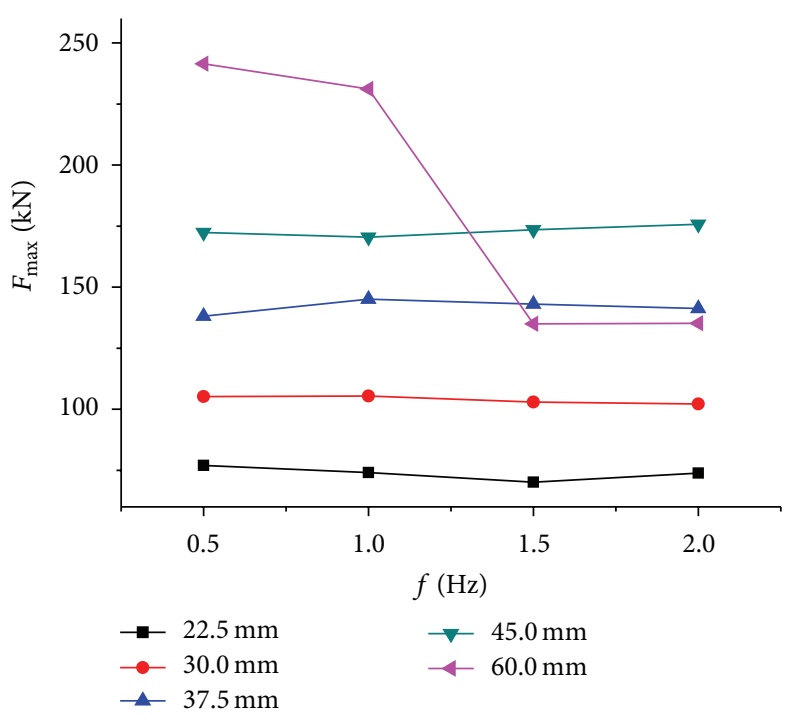

(b) Frequency dependence of the maximum damping force

FIGURE 5: The characteristics of the maximum damping force.

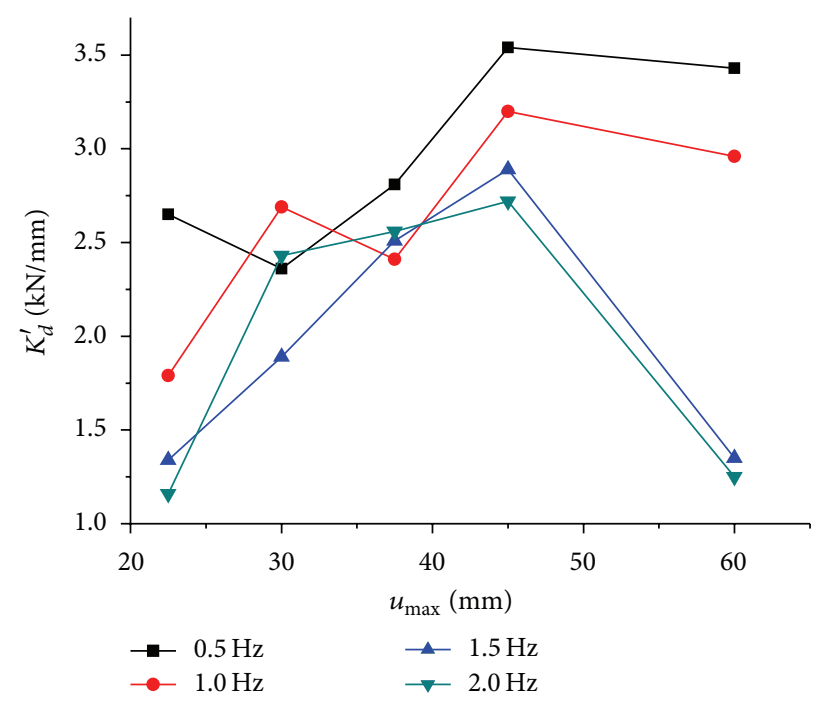

(a) Displacement dependence of storage stiffness

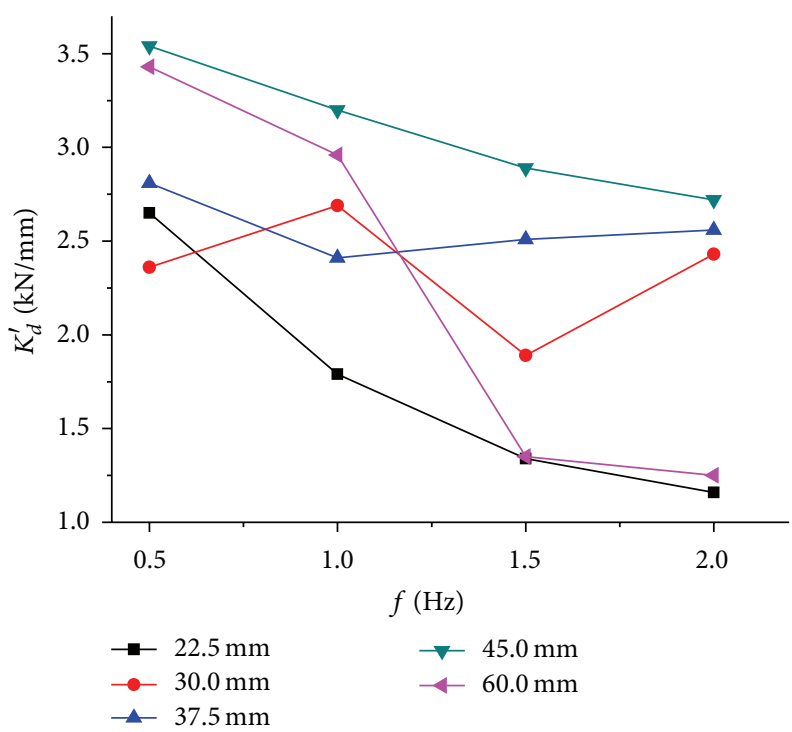

(b) Frequency dependence of storage stiffness

Figure 6: The characteristics of the storage stiffness.

$1.0 \mathrm{~Hz}$. At 1.5 and $2.0 \mathrm{~Hz}$, the maximum damping force increased monotonically when the displacement was less than $45 \mathrm{~mm}$ and decreased monotonically when the displacement was greater than $45 \mathrm{~mm}$. Therefore, the changing trend was shown to be parabolic. It can be seen from Figure 5(b) that the maximum damping force was independent of the frequency except for the largest displacement of $60 \mathrm{~mm}$. At $60 \mathrm{~mm}$, the maximum damping force decreased with the increase of the frequency.

4.2. Storage Stiffness. The storage stiffness $\left(K_{d}^{\prime}\right)$ is also termed as the equivalent stiffness, which is defined as the ratio of the maximum elastic force (load at maximum displacement) to the maximum displacement. It reflects the energy conversion capacity of the VDW. Figure 6 displays the frequency- and displacement-dependence curves of the storage stiffness. It can be seen from Figure 6(a) that the storage stiffness of components under different frequency conditions exhibited a parabolic relationship with the displacement. For four of the frequencies, the storage stiffness reached its maximum when the displacement was $45.0 \mathrm{~mm}$. The maximum storage stiffness decreased with an increase in frequency. The storage stiffness at $0.5 \mathrm{~Hz}$ was the maximum $(3.54 \mathrm{kN} / \mathrm{mm})$, whereas the storage stiffness at $2.0 \mathrm{~Hz}$ was minimal $(2.7 \mathrm{kN} / \mathrm{mm})$. It can be seen from Figure 6(b) that the storage stiffness decreased monotonically with increase in frequency at all displacement amplitudes except for 30.0 and $37.5 \mathrm{~mm}$. 


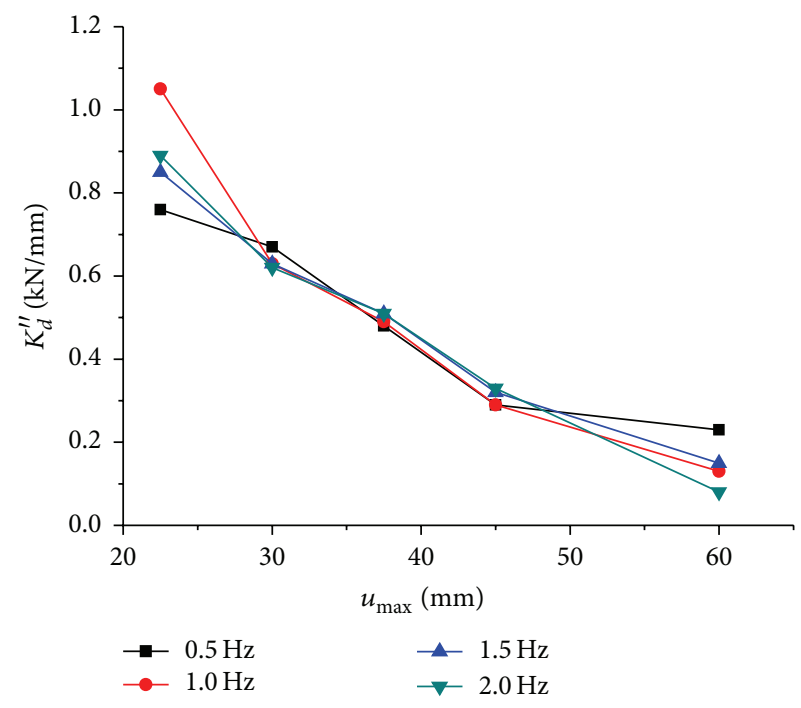

(a) Displacement dependence of loss stiffness

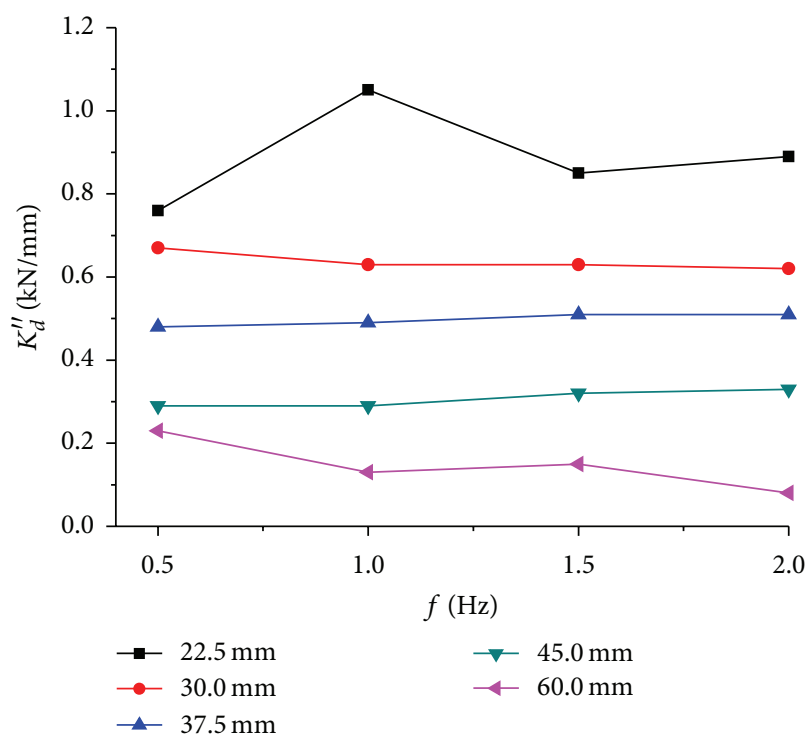

(b) Frequency dependence of loss stiffness

FIGURE 7: The characteristics of the loss stiffness.

4.3. Loss Stiffness. The loss stiffness $K_{d}^{\prime \prime}$ is defined as the ratio of the maximum viscous force (the load at zero displacement) to the maximum displacement. It describes the energy dissipation capacity of the VDW. Figure 7 shows the frequencyand displacement-dependence curves of the loss stiffness. It can be seen from Figure 7(a) that the loss stiffness of the component decreased monotonically with an increase in displacement amplitude, regardless of the frequency. Moreover, the decreasing rate is almost constant. For the frequency dependence of loss stiffness, however, the loss stiffness shows no dependence on frequency at all displacements expect for the maximum displacement amplitude at $60.0 \mathrm{~mm}$.

4.4. Equivalent Damping Coefficient. The equivalent damping coefficient $C_{d}$ is also known as the equivalent viscous coefficient. It is defined as the ratio of the loss stiffness to the loading frequency. According to this definition, the equivalent damping coefficient has a strong relationship with the loss stiffness. The frequency and displacement amplitudedependence curves of the equivalent damping coefficient are shown in Figure 8. It can be seen from Figure 8(a) that the equivalent damping coefficient of the component decreased monotonically with an increase in displacement amplitude at each frequency. The equivalent damping coefficient at $0.5 \mathrm{~Hz}$ was much higher than that at the other frequencies. However, in contrast with the dependence of loss stiffness, for each displacement amplitude, the equivalent damping coefficient decreased gradually as the frequency was increased. The maximum equivalent damping coefficient was $1.52 \mathrm{kN} \cdot \mathrm{s} / \mathrm{mm}$ when the frequency was $0.5 \mathrm{~Hz}$ and the displacement was $22.5 \mathrm{~mm}$.

4.5. Shear Storage Modulus. The shear storage modulus $G^{\prime}$ is defined as the ratio of the multiplication of storage stiffness to the viscoelastic slab thickness with the shearing area of viscoelastic material. It can be seen from this definition that the displacement and frequency dependence of the shear storage modulus showed high consistency with that of the storage stiffness. Figure 9 gives the displacement- and frequency-dependence curves of the shear storage modulus. It can be seen from Figure 9(a) that the relationship between the storage modulus and the displacement was parabolic at each frequency. At all frequency conditions, the storage modulus reached its maximum value at a displacement of $45.0 \mathrm{~mm}$. Moreover, the maximum value decreased as the frequency was increased (the maximal shear storage modulus was $3.54 \mathrm{MPa}$ at $0.5 \mathrm{~Hz}$, and the minimum value was $2.7 \mathrm{MPa}$ at $2.0 \mathrm{~Hz}$ ). In Figure 9(b), it can be seen that the shear storage modulus of the component decreased monotonically with an increase in frequency at all displacement conditions except for 30.0 and $37.5 \mathrm{~mm}$.

4.6. Shear Loss Modulus. The shear loss modulus $G^{\prime \prime}$ is defined as the ratio of the multiplication of loss stiffness to the viscoelastic slab thickness within the shearing area of viscoelastic material. It can be seen from this definition that the displacement and frequency dependence of the shear storage modulus were consistent with the loss stiffness. Figure 10 presents the displacement- and frequencydependence curves of the shear loss modulus. Figure 11(a) indicates that the shear loss modulus of the component decreased monotonically with an increase in displacement, regardless of the frequency. Moreover, the decrease rate is nearly constant. For the frequency dependence of the shear loss modulus, however, the shear loss modulus showed no relationship with frequency at all displacements, expect for the maximum displacement amplitude of $60.0 \mathrm{~mm}$.

4.7. Loss Factor. The loss factor $\eta$ is defined as the ratio of loss stiffness to storage stiffness. It is also equal to the ratio of the maximum viscous force (load at zero displacement) to the maximum elastic force (load at maximum displacement). The 


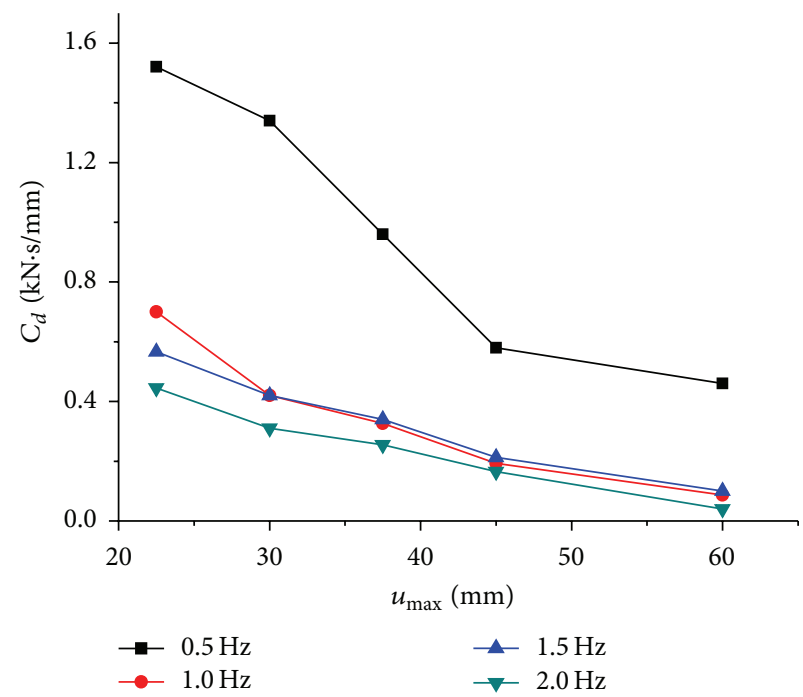

(a) Displacement dependence of equivalent damping coefficient

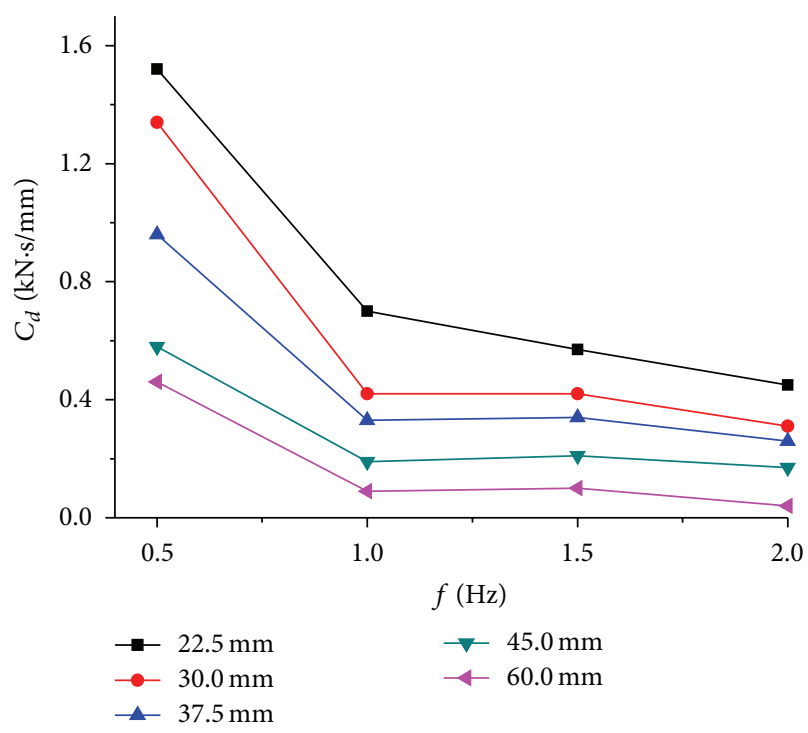

(b) Frequency dependence of equivalent damping coefficient

FIgURE 8: The equivalent damping coefficient.

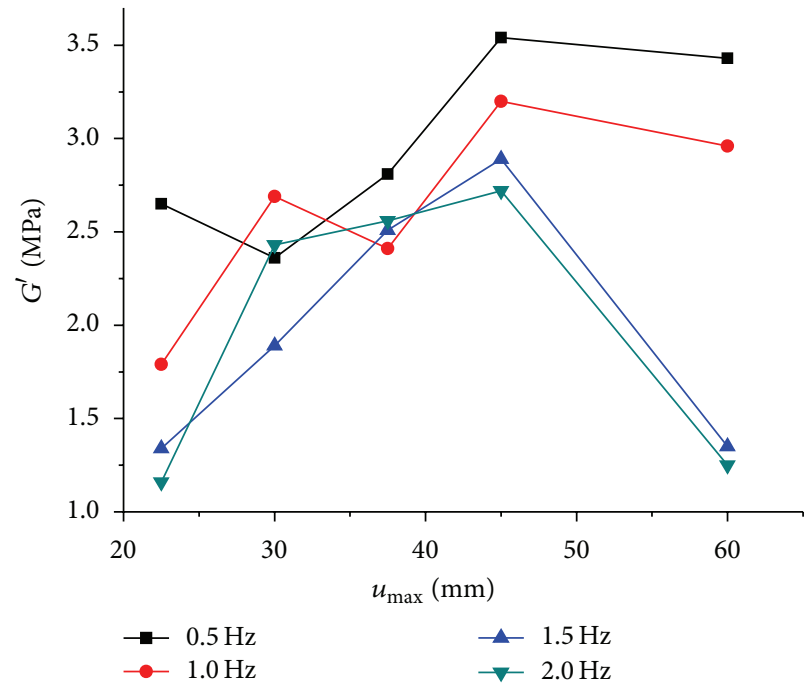

(a) Displacement dependence of shear storage modulus

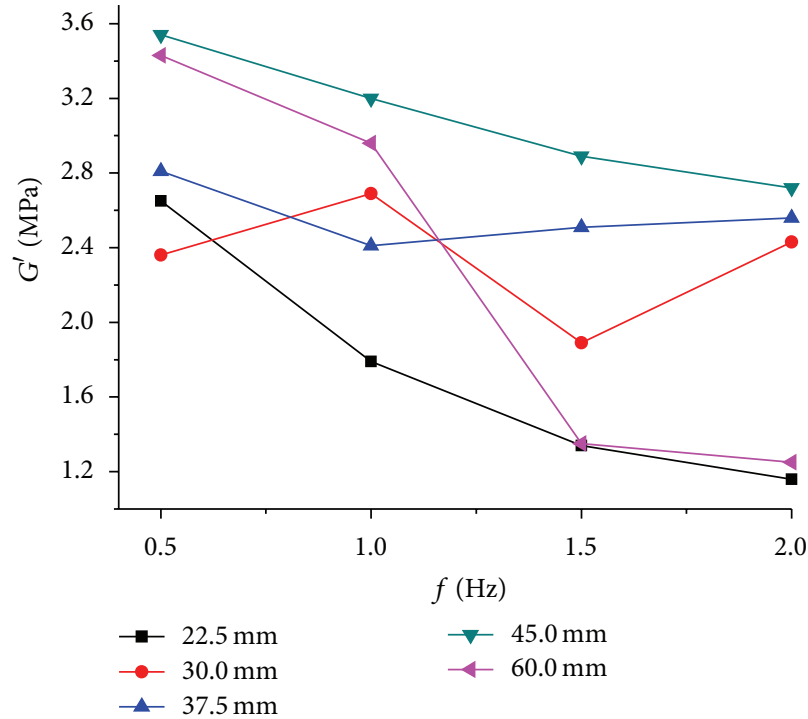

(b) Frequency dependence of shear storage modulus

FIgURE 9: The shear storage modulus.

frequency and displacement amplitude-dependence curves of the loss factor are displayed in Figure 11. It can be seen from Figure 11(a) that the loss factor decreased with an increase in displacement amplitude at all four of the frequency conditions. The peak value of the loss factor was 0.77 when the frequency was $2.0 \mathrm{~Hz}$ and the displacement was $22.5 \mathrm{~mm}$. The peak value of the loss factor, which was obtained from the temperature scan test of the viscoelastic damping material, was 0.79 . Therefore, the difference rate between them $\left(\eta_{\max (\mathrm{VDM})}-\eta_{\max (\mathrm{VDW})} / \eta_{\max (\mathrm{VDM})}\right)$ was only 0.025 , which indicates that the designed " $5+4$ " VDW exhibits a good energy dissipation capacity in shear loading mode in the transverse direction.

\section{Conclusions}

(1) A temperature scan test of the viscoelastic damping material was conducted directly in order to obtain an indirect change of the VDW component with temperature. The results were accurate and intuitive.

(2) The equivalent damping coefficient decreased with an increase in frequency, whereas the maximum damping force, loss stiffness, loss factor, and shear loss modulus showed no correlation with the frequency. The storage stiffness and shear storage modulus decreased at first and then increased as the frequency 


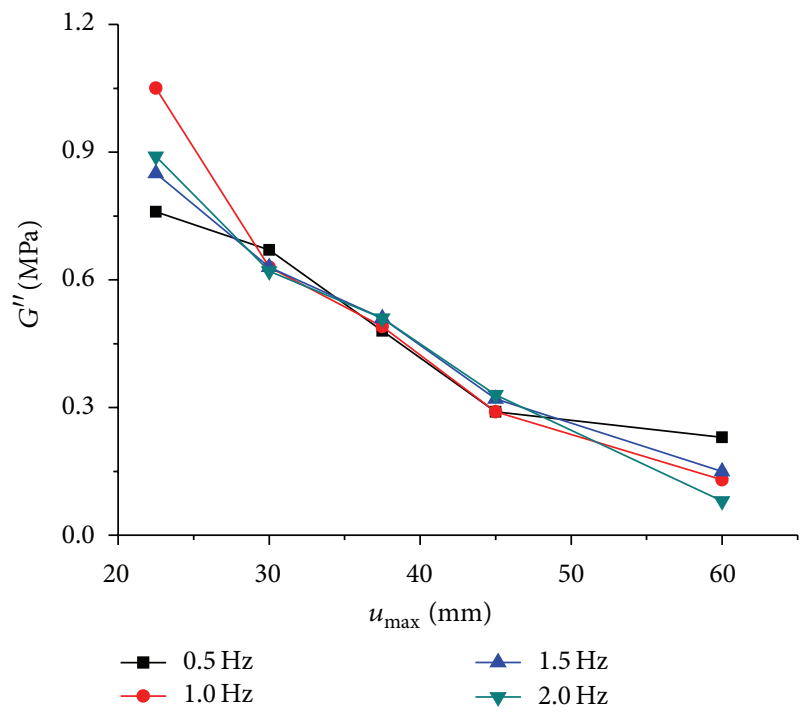

(a) Displacement dependence of shear loss modulus

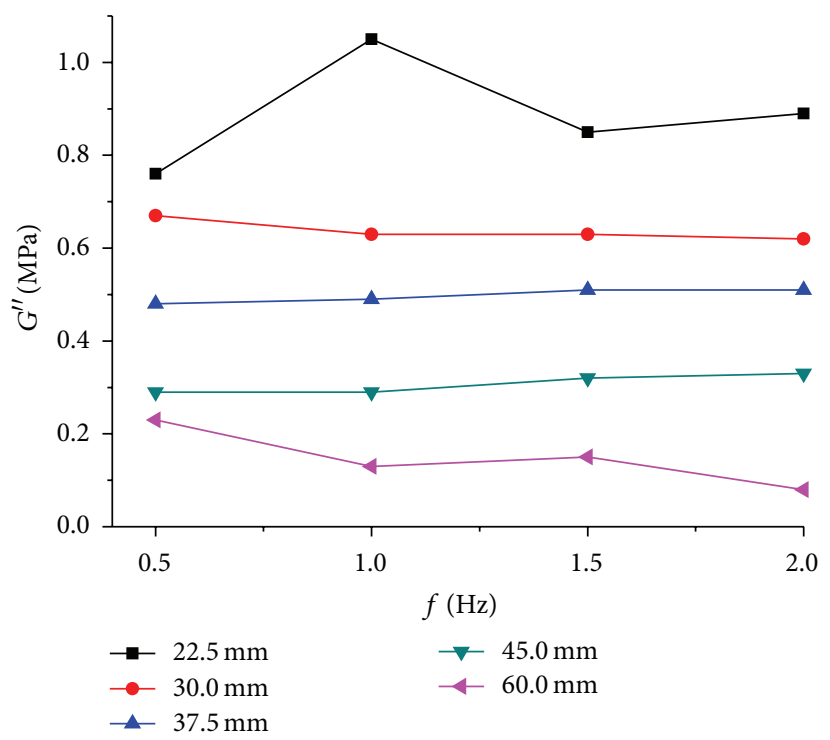

(b) Frequency dependence of shear loss modulus

FIgURE 10: The shear loss modulus.

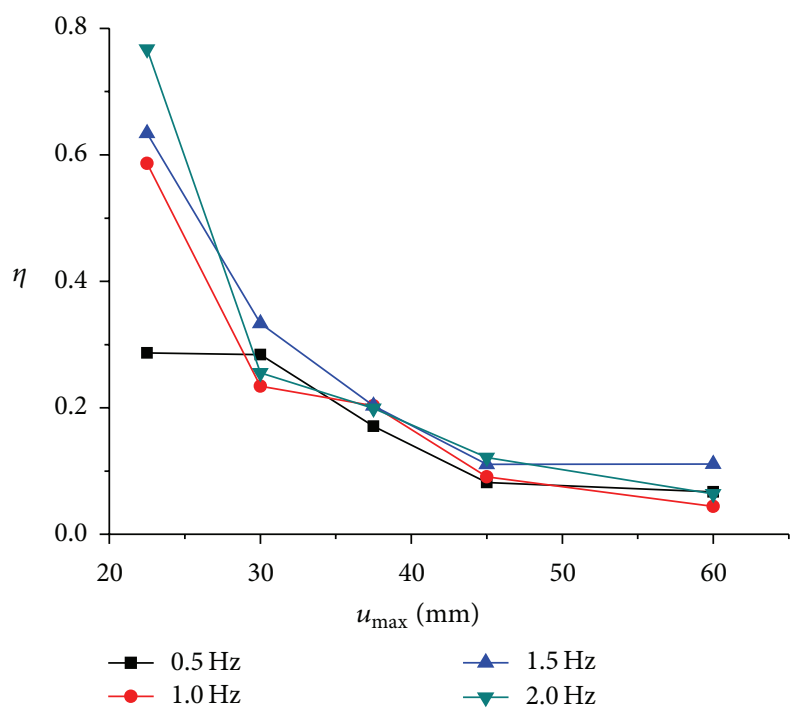

(a) Displacement dependence of loss factor

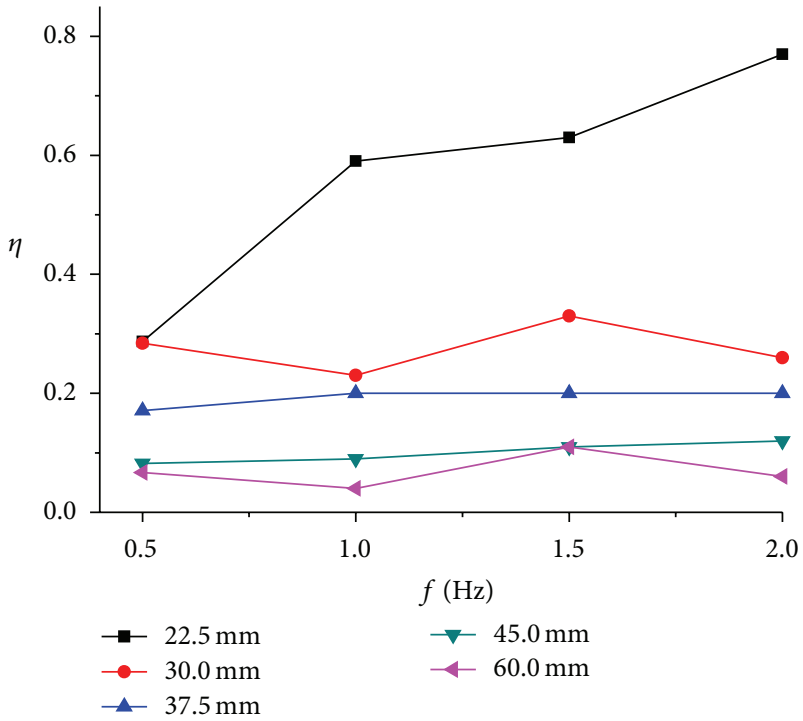

(b) Frequency dependence of loss factor

Figure 11: The loss factor.

was increased and the displacements were 30.0 and $37.5 \mathrm{~mm}$.

(3) The displacement dependence of storage stiffness and shear storage modulus was shown to be parabolic. At $45.0 \mathrm{~mm}$ and $0.5 \mathrm{~Hz}$, the storage stiffness and storage modulus reached peak values of $3.54 \mathrm{kN} / \mathrm{mm}$ and 2.7 $\mathrm{MPa}$, respectively. The loss stiffness, loss factor, and shear loss modulus decreased monotonically as the displacement was increased. The maximum damping force increased monotonically as the displacement was increased to 0.5 and $1.0 \mathrm{~Hz}$. The maximum damping force initially increased, but it then decreased when the frequencies were $1.5 \mathrm{~Hz}$ and
2.0 Hz. The maximum damping force reached peak values of $173.5 \mathrm{kN}$ and $175.7 \mathrm{kN}$ when the displacement was $45.0 \mathrm{~mm}$.

\section{Conflict of Interests}

The authors declare that there is no conflict of interests regarding the publication of this paper.

\section{Acknowledgments}

This work is supported by the National Science Foundation of China (51278104), the Key Projects of Application 
Development Plan in Chongqing (cstc2014yykfB30003), and the Science and Technology Project of the China State Construction Engineering Corporation (CSCEC-2010-Z-01).

\section{References}

[1] E. M. Kerwin Jr., "Damping of flexural waves by a constrained viscoelastic layer," The Journal of the Acoustical Society of America, vol. 31, no. 7, pp. 952-962, 1959.

[2] D. Ross, E. E. Ungar, and J. R. Kerwin, "Damping of plate flexural vibration by means of viscoelastic laminae," in Structural Damping, T. E. Ruzicka, Ed., ASME, New York, NY, USA, 1959.

[3] P. Mahmoodi, "Design and analysis of viscoelastic vibration dampers for structures," in Proceedings of the World Innovative Week Conference (INOVA '73), pp. 25-39, Ed. Eyrolles, Paris, France, 1973.

[4] E. J. Nielsen, M. L. Lai, T. T. Soong, and J. M. Kelly, "Viscoelastic damper overview for seismic and wind applications," in Proceedings of the 1st World Conference on Structural Control, Los Angeles, Calif, USA, 1994.

[5] P. Mahmoodi and C. J. Keel, "Performance of structural dampers for the Columbia Center Building," in Building Motion in Wind, N. Isyumov and T. Tschanz, Eds., pp. 83-106, American Society of Civil Engineers, New York, NY, USA, 1986.

[6] J. E. Cermak, H. G. C. Woo, M. L. Lai, J. Chan, and S. L. Danielson, "Aerodynamic instability and damping on a suspension roof," in Proceedings of the 3rd Asia-Pacific Symposium on Wind Engineering, Hong Kong, December 1993.

[7] C. Wenrang, S. Jieying, C. Yueming et al., "Design and study on earthquake absorption using viscoelastic damper in transportation building of Suqian City," Journal of Building Structures, vol. 21, no. 3, pp. 30-35, 2000.

[8] K. C. Chang, T. T. Soong, S. T. Oh, and M. L. Lai, "Effect of ambient temperature on viscoelastically damped structure," Journal of Structural Engineering, vol. 118, no. 7, pp. 1955-1973, 1992.

[9] K.-W. Min, J. Kim, and S.-H. Lee, "Vibration tests of 5-storey steel frame with viscoelastic dampers," Engineering Structures, vol. 26, no. 6, pp. 831-839, 2004.

[10] T. T. Soong and G. F. Dargush, Passive Energy Dissipation Systems in Structural Engineering, Wiley, New York, NY, USA, 1997.

[11] X. Tan, Vibration control of structures with viscoelastic dampers [Ph.D. thesis], Hong Kong Polytechnic University, Hong Kong, 1998.

[12] L. Aiqun, Vibration Control of Engineering Structure, China Machine Press, Beijing, China, 2007.

[13] K. C. Chang, S. J. Chen, and M. L. Lai, "Inelastic behavior of steel frames with added viscoelastic dampers," Journal of Structural Engineering, vol. 122, no. 10, pp. 1178-1186, 1996.

[14] G. Zhao, P. Pan, J. Qian, and J. Lin, "Experimental study of viscoelastic dampers subjected to large deformation," Journal of Building Structures, vol. 33, no. 10, pp. 126-133, 2012.

[15] Z.-D. Xu, D.-X. Wang, and C.-F. Shi, "Model, tests and application design for viscoelastic dampers," Journal of Vibration and Control, vol. 17, no. 9, pp. 1359-1370, 2011.

[16] D. M. Bergman and R. D. Hanson, "Viscoelastic mechanical damping devices tested at real earthquake displacements," Earthquake Spectra, vol. 9, no. 3, pp. 389-417, 1993.

[17] P. Crosby, J. M. Kelly, and J. P. Singh, "Utilizing viscoelastic dampers in seismic retrofit of a thirteen-story steel framed building," in Proceedings of the ASCE Structures Congress XII, vol. 2, pp. 1286-1291, Atlanta, Ga, USA, April 1994.

[18] T. T. Soong and B. F. Spencer Jr., "Supplemental energy dissipation: state-of-the-art and state-of-the-practice," Engineering Structures, vol. 24, no. 3, pp. 243-259, 2002.

[19] H. Choi and J. Kim, "New installation scheme for viscoelastic dampers using cables," Canadian Journal of Civil Engineering, vol. 37, no. 9, pp. 1201-1211, 2010.

[20] M. C. Constantinou, P. Tsopelas, W. Hammel, and A. N. Sigaher, "Toggle-brace-damper seismic energy dissipation systems," Journal of Structural Engineering, vol. 127, no. 2, pp. 105-112, 2001.

[21] A. N. Şigaher and M. C. Constantinou, "Scissor-jack-damper energy dissipation system," Earthquake Spectra, vol. 19, no. 1, pp. 133-158, 2003.

[22] C.-G. Cho and M. Kwon, "Development and modeling of a frictional wall damper and its applications in reinforced concrete frame structures," Earthquake Engineering and Structural Dynamics, vol. 33, no. 7, pp. 821-838, 2004.

[23] X. Lu, Y. Zhou, and F. Yan, "Shaking table test and numerical analysis of RC frames with viscous wall dampers," Journal of Structural Engineering, vol. 134, no. 1, pp. 64-76, 2008.

[24] China Standard Press, "Dampers for vibration energy dissipation of buildings," JG/T 209-2012, China Standard Press, Beijing, China, 2012.

[25] The Japan Society of Seismic Isolation, Passhibu Seishin Kouzou Sekkei. Sekou Manyuaru Sono, The Japan Society of Seismic Isolation, Tokyo, Japan, 2008. 


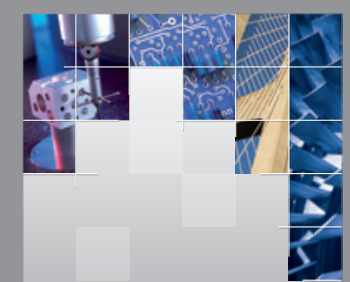

\section{Enfincering}
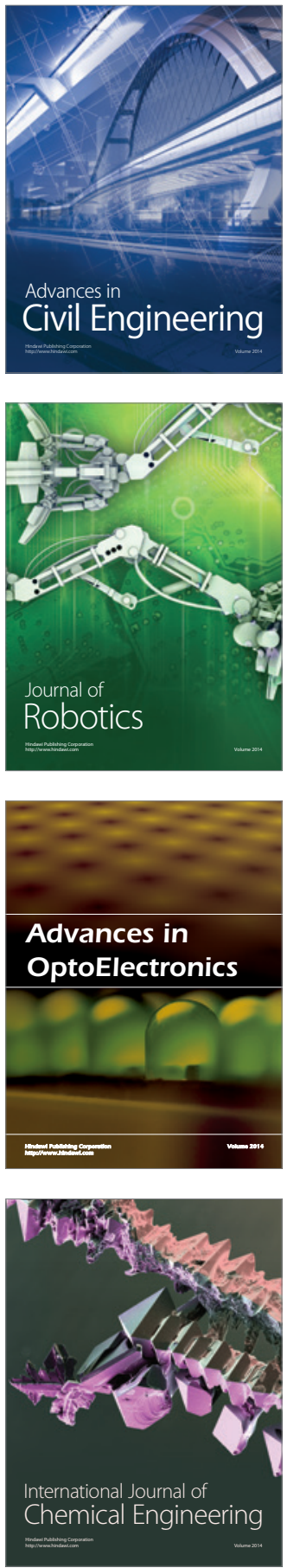

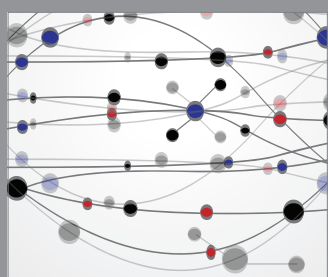

The Scientific World Journal

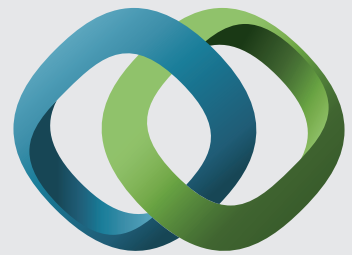

\section{Hindawi}

Submit your manuscripts at

http://www.hindawi.com
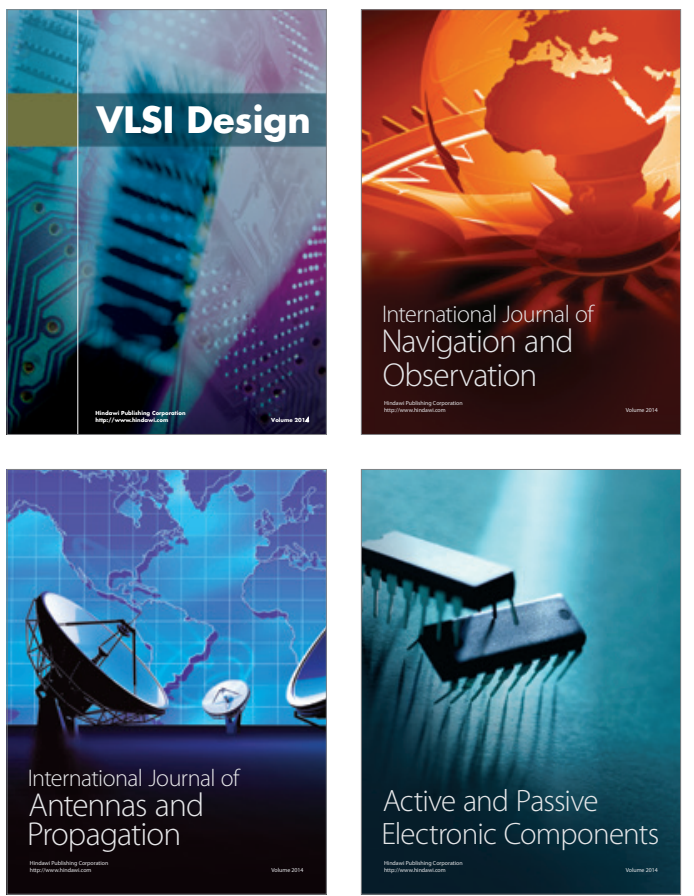
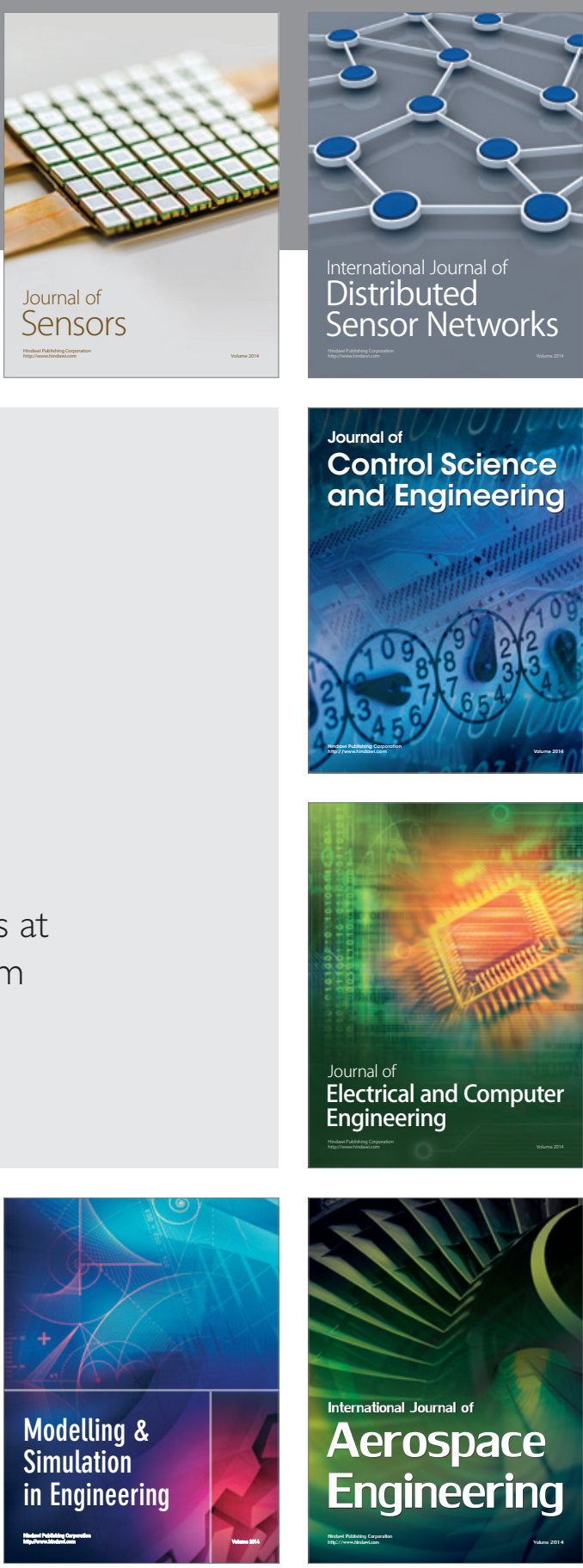

International Journal of

Distributed

Sensor Networks

Journal of

Control Science

and Engineering
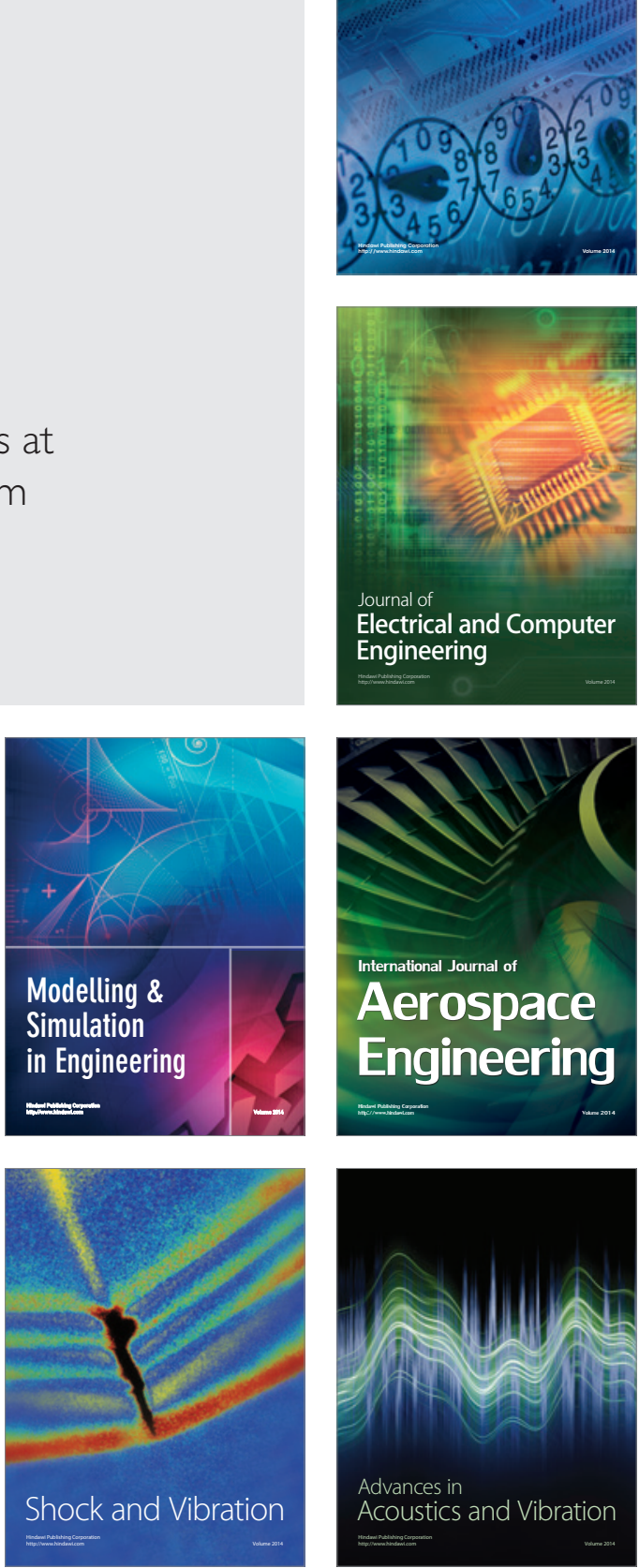